\title{
STANDARTS AND DYNAMICS IN SPORTS WEBSITES ONLINE EDITING
}

\author{
Efrem Karanfilov
}

Sofia University „St. Kliment Ohridski”, Bulgaria

\begin{abstract}
This text covers theoretical and practical problems of the sport's editor work in the conditions of media convergence. It provides analysis of issues, such as the trustworthiness of journalistic sources, the use of the social networks, the editor's new functions and responsibilities. Another approach is the tendency for emphasizing more on the visualization as a message, which reveals completely new influence over the perception of the information and its influence for mind shaping among the society. The methods of research are based on content analyses, comparative analyses and historical review. The main researched objects are the technology of editing and framing the information in the modern media. The text combines theoretical knowledge and description of typical practical solutions, which editors may wish to apply in their day-to-day work.

The main importance is given to presenting the rules and practices which combine the journalistic principles and the requirements of the technologies, which are challenging the personality of the journalists to have a wider and deeper all round preparation both in the humanitarian area and in the specific aspects of sport competition, and second - the operation skills, taking into consideration the modern aesthetical and technological tendencies in the media based on Internet communications.

The research is based on the keys of media journalism in Bulgaria and selected media from Europe and USA from the recent years.

It is the first investigation in the field of online editing in the sports media in Bulgaria and will serve as a guideline for further scientific research. It is also considered to be informative for the methodical practical preparation of sports journalists.
\end{abstract}

Key words: Sports journalism, editing, trustworthiness of sources, headline variability, facts check-up

\section{INTRODUCTION}

There is no need to prove the link between media and sports. It is obvious and constitutes an integral part of the social impact of sports. Every achievement, sports record or victory is made known to the public through the media. This is a key reason why many ex-sports-persons would opt for sports journalism after they end up their active career. As it is well known, to be an anchor, author and sports caster is the facade and the most popular aspect of a sports journalist's profession. But the basic part of the job is editing, selecting topics and presenting them in a manner most accessible to the audience. This is the big responsibility of a sports journalist and journalism in the contemporary society.

It is a challenge in the modern changing world for an online editor to epitomize the main skills indispensable to the sports media while the new technologies require a completely different qualitative and conceptional approach of online journalism. 


\section{New challenge}

It was not so far back over the years, in 1992, when, with AOL support, the Chicago Tribune uploaded its first information pages on the web. A year later, the San Jose Mercury News became the first edition granting free online access to its readership. The relationship between the media and the Internet started coyly, went through various stages and developed rapidly. There were triumphant times, but also times of doubts whether they were made for each other. In 2000, the CNN employed 750 staff members for the television's interactive division (as it used to be called back then). Newspapers followed in the wake. Over 60 journalists worked only for the Internet version of the Wall Street Journal, 50 were employed for the USA Today, 40 joined the New York Times (DeTarle, 2006). The media's "jump" into the network was not a financially lucrative move. The New York Times, the flagman of American journalism, had a 50-million-dollar loss in the same year resulting only from the redeployment and management of online journalistic resource. Users were few and so were ads.

In 2003, the media-technologies affair had its sudden upturn. Web 2.0 was launched allowing for a qualitative technical upgrade. ADSL networks were in mass distribution. They handled the transfer of large data volumes to people with ease and speed. The Google search engine was launched making it easier than ever to locate online content. Large photo and music platforms became operational, such as Flickr and YouTube. Amazon and eBay established themselves as the first giant e-trade brands. The world took a sudden turn to its virtual self and journalism had nothing else to do but follow it. The mass penetration of contemporary mobile phones allowed access to everything for everybody, the incredible spread of the social networks only cata- lysed this process.

Today, journalism and the Internet are closely interconnected. It might be symbolically described as a marriage of convenience, where classical journalism retreats from its position to gain the advantage of immediate response to events, so that readers get the information right away. The big global crisis which struck the printed media, however, shows how much journalism had actually lost in terms of jobs, falling circulation, a shrinking share of ad income. Meanwhile, a number of editions overcame the effects of the shock.

The journalism-Internet bonding faced editors with new professional challenges, mostly related to checking the credibility of online circulated information, the elimination of the so called "fake news" disseminated in the pursuit of certain political or economic interests. Also, "civil journalism' appeared as a reflection of readers" square refusal to be the mere passive consumers of information. Special attention had to be given to social networks as the pool for winning a broader readership, but also as a vast information resource, which could be utilised with caution and measure.

\section{Purpose and objectives of the study}

This research aims to present the tendencies of development of online editing in sports journalism concerning the development of the modern media technologies and their reflection over the classical methods of editing in sports journalism.

Major attention will be given to presenting the different models of contemporary online editing techniques in the media.

\section{Main thesis and hypothesis of the research}

Modern sports journalism is a dynamic profession which is challenged from the rapid, multicultural, and social development of sport as a world phenomenon undertaking new functions in its social impact of the modern civili- 
zation. At the same time, the technological and conceptual development of modern media as factor for designing the mind and behavior of the societies, its concentration in international media industry is placing the sport journalist in a very dynamic and responsible position to operate and design information. The sport journalist now must accept the idea of life-long learning and gaining knowledge, skills and experience not only about the great diversity of sport as cultural phenomenon, but also about the editing, framing and presenting the great amount of information about the development of modern sport. This is why, the modern sport journalist must be prepared to operate technically with information and be capable to convey the messages dealing with the native socio cultural function of sport as phenomenon in the modern civilization, to spread human values, and to give the society and especially the young generation the strive for perfection, moral skills aiming to create a more peaceful world.

\section{METHODS}

\section{Checking information sources, concepts,} and research

Contemporary online journalism presumes "piling dead stock in the editorial office" (Estienne, 2007), whereby the perception of modern information sources is getting more and more ,visualised” (Davis, 2009). This new pace of work, the avalanche amassment of the information flow, the social networks - it all pertains to the issue of source credibility, inasmuch as the presentation of facts could be trusted and correspond to the objective truth about the event occurring.

I would uphold that achieving full objectiveness is a hard thing. To say the least, a journalist conveys reality in words or photography and chooses what to voice and what to silence. To abide by professional standards though, does not mean to tell the truth, but to render a best approximation of it. When sports journalists in a particular edition (print or online) try to approximate the truth in every text they write, this means that the edition is a reliable source. It can be trusted and quoted. Mostly because reliability is not a one-off act, but corresponds to the mission, the essence and the style of the edition.

Certain western surveys have introduced the term "credibility" (Wathen et Burkell, 2002). They maintain that "The credibility of a message is the result of the interaction between the characteristics of a source and those of the recipient" (cultural background, initial attitudes, etc). Reich subscribes to a similar statement (Reich, 2011).

Life in the Clickstream, a report by Este, Warren et al. (2010), reveals and analyses the results of indicative polls. In Australia, radio stations have earned the greatest share of public confidence $-84 \%$, respectively, $81 \%$ of the audience trust the Internet, $80 \%$ trust television and $70 \%$ trust the printed media. European surveys reveal more shocking results. The Gallard et Petit TNS barometer (2015) shows that $57 \%$ believe that the radio provides them with credible information, while only $35 \%$ trust websites.

Regular social surveys in all EU member states show similar results. Radio is the public trust leader with over $50 \%$, followed by the printed media with $45 \%$, televisions with $42 \%$ and websites rank last with only $33 \%$ (Eurobarometer 72, 2009, 2011, 2015). Dozens of similar surveys present similar data. A large share of the audience obtains information from the web but mistrusts the sources. The audience trusts certain editions or certain people.

In my opinion, the reason for these results, which reveal people's lack of certainty about online information, is that this information is 
not reliable, it is not secure, it is not "credible".

\section{The verification problem in journalism}

Every specialist in the profession would be aware that the problem arises mostly from time pressure. The major tools for verification, writing and editing are the same as in printed journalism, but on the Internet it all happens (as a technological process) over a critically abridged timescale. Competing to be the first who posted the news in the media market often triggers a violation of good practices.

Moreover, most web pages have less "levels of review" and "validation" for a text than printed media. Editors are overloaded with more tasks and, adding the time pressure, we have the reasons for errors, impressions, posting unchecked information, etc.

It is an interesting fact that information agencies tend to occupy a yet bigger share in the transfer of information to the end user. Websites act as intermediaries and they often rely on the fact that their colleagues have already checked the initial information which does not always occur in practice. Also, journalists often seek tacit assistance from their competitors by finding out if they have checked and published the information.

Another source of information has also emerged for journalists, which is tending to less and less be treated as merely "a source of information" pending to be checked and validated by journalists. It is beginning to transform into the ,editor-in-chief” - the social networks.

Due to the radical change brought forth by information technologies not merely in the area of communications, but in any sector of human life, the world has "shrunk". The penetration of new technologies has changed the market, the impact of the branches of power and consumer behavior.

The new generation of mobile phones has brought the continents, states and "hot spots" closer, while through the social networks, (almost) every human being has become a broadcaster of information. This is a fact because a mobile phone with an inbuilt Internet connection can be used both as a telephone and a tuner, it can receive photos, radio and television transmissions. These changes have created the opportunity for developing new content and services and have dramatically changed consumer behavior, as well as the media-consumer relationship, which has become interactive - consumers have become "the media" and the media have begun to use consumers' messages.

Sometimes photography and a summary of a "hot event" (an accident, a terrorist act, a murder, etc.) which are, naturally, subjective and often imprecise and not based on trusted and verified sources, would appear in the social networks before even the best global agencies' response. Sometimes, however, this information is the same as the one an agency would publish in the first minutes of a certain unforeseen event.

However, an eye-witness has already posted a video on the networks, which was seen and shared by thousands and any follow-up information from an agency or any other media is treated as secondary, no matter it may contain the exact number of victims.

More and more editors-in-chief or editorsin-charge would assign journalists with comments and analysis of topics spurring the most comments of "likes" in the social networks. Where do we draw the boundaries of editorial policy then, what about the social function of the media? The news of a blood-soaked killing would gather a much higher number of readings on the Internet than the debate over a differentiated VAT rate for Bulgarian books. Therefore, the need for a healthier dosing of the networks dictates the "rating" of news, 
which are to be delved into, analyzed and commented on. There is no accurate prescription for the ratio; it depends on editors' preparation and experience.

Not a single editor or a website would err if they based their actions on healthy skepticism and on the basic founding rules of press journalism.

There are different techniques for checking information sources on the Internet. As a firststep, New York Times journalist Stephen Miller suggests checking MIDIS (Miller Internet Data Integrity Scale), a website scale. It is based on the website URL extension. The author claims that the most reliable sites are those ending in "gov", "govt" or in national acronyms, such as "bg". These are followed by the websites of various organizations or interest groups ending in "org", "net", etc. The author warns that they might often defend private interests. The sites ending in 'com', 'co', etc. are labeled as least reliable. Other researchers (Friend and Singer, 2007) accept this qualification without claiming that it is universally applicable.

If editors look for information on the web and come across a certain website, they should necessarily ask themselves the following questions:

- Who works for it? Most websites have a "Who are we?", "About", "Team", etc. tab. If no such reference is available and there is only an e-mail for contacts, the irregularity suspicion is confirmed. A website containing only unsigned information postings and comments is more than suspicious.

- Who says this? The website must provide opportunities to trace back quoted information: a governmental department, an institution, a public figure, another website.

- When was this website last updated? This is also an important indication about its performance.

Of course, there are also other ways of conducting a check: through hyperlinks and metadata analysis, an IP address check, where possible. In the case of suspicious photos or videos, specialized software could be used to check if they have been tampered or even to trace the transformations a certain image might have undergone.

The Internet has given us a lot of opportunities, but it has gradually transformed part of the profession in desktop journalism, which acts as the intermediary between the readership and the information sources. In any case, some more healthy skepticism to the news flow will always be of good use. This rule applies mostly to the editorial websites claiming to disseminate true and verified information, and not to those with the fake news, rumors or sensations.

\section{Civil journalism and the editorial process}

The beginning of the $21^{\text {st }}$ century saw real disruptions in journalism. It was not merely the existence of the Internet. The dissemination of modern technologies lead to two new phenomena: civil journalism and the social networks.

People have already abandoned their passive-news-consumer patterns but began to create media content themselves. The media themselves have evolved from their full dominance over information to a domain shared with readers. This process resulted in actual changes of the conventional labor organization schemes and audience public relations. A lot of practices have changed. „Journalism and the journalist as a professional had become the focal point of a transformation, which challenges the customs and traditions untouched by today, whereby the civil media hold the central position." (Shudson, 2003).

There are various opinions about the origin of ,civil journalism”. Some say (Curran and Seaton, 2010) that it shares certain features of the reformation newspapers in England at the beginning of the $19^{\text {th }}$ century. The journal- 
ists in those papers ,proclaimed themselves non-professionals but stood rather as people upholding a civil position" (Harrison and Barthel, 2009) maintain almost the same view believing that even back then, citizens somehow assisted in the creation of media products ,for the benefit of community initiatives and social products". It is interesting to observe that the desire for equality between a journalist and the audience emerged in the USA private radio stations, as propounded by "New Journalism" and the local media in the US in the 60s (Paullussen et al., 2007). Others (Douglas, 2006) state that 'Civil journalism was born on 7 July 2005'. This was the date of the London subway attacks. There were no official shots, but the BBC was overwhelmed by 22 thousand text messages and 300 photographs and videos by eye-witnesses. The corporation had been showing these for a full day and according to the author, ,this was the first official amassment of information and its use in official channels". Practice reveals that this was the right decision. Williams (Williams et al., 2010) summarizes that "The BBC choice then was in favor of the audience revolution." Although it was exactly the BBC, which had been blamed of using information from Twitter in its coverage of the Bombay 2008 attacks, the corporation continues its practice of referring to unofficial information sources.

Nowadays, we can hardly imagine journalistic activity without the use of the readers and the social networks. The first media responses to the collapse of the Tunisia and Egypt regimes or to natural disasters, such as the Fukushima accident or the Haiti earthquake, came exactly from these sources. Thereby, I shall accept as correct Bowman and Willis' definition of civil journalism: "An action enabling one citizen or a group of citizens to play an active role in the process of creation, selection, analysis and distribution of information and news" (Bowman and Willis, 2003). Of course, dozens of definitions exist, and they have their scientific value.

Readers enjoy a growing share in drafting the media agenda. But not an absolute one. In 2011, a survey was conducted among 20 national dailies in $10 \mathrm{EU}$ member states. The goal was to study the audience participation in the creation of the final product. The process was split in the following stages: access and monitoring, selection and filtering, processing and publishing and interpretation. The results were similar, and they showed that "the first and the last stages were most open to reader participation" (Singer, 2011). This shows that the true publishing process was left to the professional editors. Along the same lines, all ranking systems have adopted the criterion of "most read" or "most commented on" text as an important, but not a critical one for the editorial. Definitely, the number of visits to a certain website and the span of readers' attention for a certain text have an influence on advertisers, but do not play a decisive reason.

The combination of professionally processed information products and user-prompted content seems to be the best-balanced compromise between the time for checking a particular fact and its publication. If the media do not want to spread rumors and inventions and if editors want to work professionally with news and not fakes, then the principle of "Publish first, check second" must be forgotten. This practice is the precisely the detonator, which can blast any edition's media reputation. It is the editor's role and responsibility to prevent this.

\section{Social networks - resource and circula- tion}

Many social surveys show that the social media have become the main media channel. It is still being debated whether they comprise individual media or merely a channel, 
but practice shows that $75 \%$ of the American Internet users receive their media information on the Internet (Purcell et al., 2010). Almost half of the Canadians, $43 \%$, also receive it through sharing or a friend's recommendation (Hermida et al., 2012). Most developed countries show similar results. Something like a secondary or tertiary news market seems to exist. On the one hand, news is published in printed issues or on websites. Thereafter, they penetrate the social networks with headlines and layout inviting the audience to share, thus re-expanding the reader base.

On the other hand, social networks are a vast information resource for the media. There they can find everything - from political statements (President Trump's tweets are a particular case), opinions and comments of leading experts and colleagues. They can find image material and various videos. The typical thing is that authors in the social networks respond very fast, and their messages outreach a significant number of people.

More and more factors of social, political and sports life tend to express themselves in the social networks as the most direct channel of gaining direct impact on their audiences' eyes and minds. This, however, eliminates journalists as the intermediaries and it also eliminates the opportunity for asking inconvenient or clarifying questions on a certain topic or issue. Facebook and/or Twitter statements exclude the "friendly media", since their effectiveness is significantly minimized.

It is for a reason that journalists are „friends” (Facebook) or followers (Twitter) of many politicians and sports and show-business stars. And they gladly circulate their responses on numerous problems. Some say that the mass use of the social networks as an information source results in the erosion of the profession's fundamental principles, such as checking the facts, the use of documents, inquiry. I don't believe that these observers are right, as similar concerns spread around when the Internet widely penetrated journalist practices (the end of the 90s) and when blogs appeared at the turn of the century. Then, they also became a key information source and did not distort the profession's major principles.

The multitude of social networks only provides a wider range of information sources. Of course, an editor must be on the alert, as these sources also multiply the opportunities to manipulate the media. The routine: a social network posting which is circulated by the media and thus institutionalized, followed thereafter by a governmental decision, is a classical scheme of promoting political, economic or personal interests. It should not be forgotten that any account on social networks can be hacked and that celebrities have numerous fake accounts.

However, when fundamental editing rules and professional ethics are rigorously observed, then it is all to the reader's benefit.

\section{RESULTS AND DISCUSSION \\ The online sport's editor functions and duties}

Editing online publications depends on the factors shown below. Firstly, it's the website type. Websites are mainly: informative, informative-analytical, informative-entertainment, niche (such as recipes, leisure, travel, sports, technological, financial, etc.).

A typical feature of niche websites is the requirement for editors and journalists' expert knowledge as these sites are presumably read by people with specific knowledge on the subject, who prefer to gain more added value on it. The website type predetermines its target audience groups: age, social and/or professional features. The website layout is also technically important-a homepage, a mobile app, etc. For financial reasons, many sites in Bulgaria have 
no mobile app or social network sharing options (Facebook, Twitter, Google+). What users see online is predetermined by the graphic design of a website.

Informative websites - publish up-to-date information in the subject area of the website. In addition to ensuring information flow coverage, the staff of these sites is supposed to track the developments of any current events.

\section{Lead}

The structure of a lead is similar to that in the printed press - in reply to the 5 questions. Information here, though, changes "on the go", with the change in circumstances. Commentaries and analyses are supplemented.

The advantage of this site is that you can put anything in the text: a video, an audio file, statistics in the form of info-graphics, etc., i.e. the rules of press journalism are violated.

However, you have to know the rules very well to be able to break them the right way.

The language of news writing invariably follows several requirements: clarity and simplicity, in the first place, noting that these rules are twice as strong on the Internet. Always use the words in their primary and not in their figurative meaning, avoid complex words and concepts which the reader would find difficult to understand - neither jargon nor vernacular registers, but just ordinary informative language.

Unlike the printed editions, which allow for a more sophisticated and lofty style, online news and information must first satisfy the requirement of clarity and simplicity, which brings them closer to the language of radio and television news scripts.

A commentary and information lead is only possible if the author has enough expertise on the subject.

\section{Example:}

„Grigor Dimitrov dropped to be 43rd on the ATP rankings, scoring his poorest since 2012, with the prospect of sliding even further down if he fails next week".

Where there are developments in an ongoing event, it is recommended that information be updated at least every 20 minutes. If the event is exceptionally dynamic - a terrorist act, a natural disaster, etc., then its updating is almost continuous. The lead is changed and the headline states that information has been updated. The old headline may be preserved. Video embedding is also necessarily mentioned in the header.

Sometimes, the new information is completely the opposite of what was initially stated. In such cases, certain sentence qualifiers expressing doubt should be used from the very beginning: "Initial data shows" ,, is/are known at this time..." etc.

If it is an important piece of news, but little is known yet, only a lead is published plus: Details to come.

\section{Example:}

Boryana Kaleyn and Katrin Taseva lead the ranking in two apparatuses of the Rhythmic Gymnastics 2019 World Cup. Details coming soon.

If there is a qualitative change in the circumstances of the event being tracked, the header is changed. However, it is important that the revised title contains some key words from the first one. (Usually, a geographical location, a personal name, etc. clearly distinguishable and established for the user's mind.)

\section{Example:}

Revision 1, at the beginning of the event: Ludogorets is losing by 0:1 with CSKA after playing for 45 minutes in the Bulgaria Cup match between the two teams.

Revision 2: Ludogorets were yet not able to gain supremacy over the CSKA in the second half.

Revision 3: CSKA plays at the Bulgaria Cup semi-finals after winning by 1:0 against Ludogorets. 
Revision 1, at the beginning of the event: PAOK about to become champions after 34 years.

Revision 2: A wild party in Thessaloniki! PAOK won the championship for the first time this century.

The information update includes: a factbox (the editor gathers all known facts in the case and complies them in a separate box). If no such option is available on the website interface, they could be highlighted by a varied background, font, etc. or separated in a separate subtitle.

Practice shows that a lead, which is of extreme importance for Internet disseminated information, must be up to three lines long, at best (from 10 to 15 words, including conjunctions). Its importance is that it can invite a reader to continue reading or make them move elsewhere, which is registered in the time spent on each item. It is unlike the newspaper: once you have bought it, you read it, sooner or later.

Quotations are generally avoided in leads. It could be informative, or it could have a commentary aspect, but preferably, precision and clarity are sought.

\section{Example:}

CSKA published quite an interesting video on the social networks showing the referees' bias against the team in the matches with Levski and Botev (Plovdiv).

CSKA's leadership published a video on the social networks showing selected footage from games where it believed the team had suffered damages from referees' bias. (information lead)

It is recommended that the reader has a full view of the sentence and would not need to use expanding options for reading it to the end.

Every 2 hours, if the team is sufficiently staffed, the known facts and comments are summarized and the most important and significant ones are sorted out: institutions, af- fected parties, eye-witnesses. This can be done by using:

- A chronological approach, tracking the development of an event by hours.

- Introducing a commentary element: statements of officials, experts, affected persons, eye-witness reports, including tweets, using the embed function, videos.

- A reference link to previous publications is a must, or the preceding publications must be uploaded and visible in the current publication.

- The desirable volume is the length of a newspaper page, about 30 lines.

- From a commercial viewpoint, the reader's attention must be kept for longer than 30 seconds. This depends on the content you offer. It is well known that on the Internet, content is 'the king'. Google prefers content-rich websites, a survey points out.

(The SEM Group analyze the top 10 search results for over 20000 key words and identify a repeated pattern.)

The average length of a web page content ranked in Google's top 10 key-word search hits would be 2000 words at least. The higher up you climb on the ranking list, the bulkier content sites offer, Webcite.bg says.

There are numerous click bait headlines, which appetize readers' interest, but they are more typical of the sensational pages ("yellow", fake news, etc.). Their goal is to trick the reader into visiting a web page and generate traffic. On many occasions, the information supplied is different from the title, far less "sensational" that the headlines claim. No editors are required for such websites. They benefit from people with perverted minds, unscrupulous morals, who entirely lack professional ethics. The present pages are not intended for them...

Examples:

1) An insult against Beckham! Supposedly, 
he would look like this in 2020... (PHOTO)

2) You won't believe it! Russia's French passion in is so strong that...

3) A big-boobed chick blames a football star of sexual harassment (PHOTO)

Traffic generation is aimed at advertisers, but real and serious advertisers do not advertise on yellow pages. Some are interested in the number of visits (unique visits), the more serious ones consider the time a reader spends on a website.

It is good to know that all refreshments are visits, but only one counts as "unique". For instance, if you visit a web page twice from the same IP-address, this makes two visits, but only one is unique.

An important specific feature for the online editor's work is to be aware of the brand's positioning on the Internet. Content matters immensely for the search engines because it has a decisive say in the websites index ranking. Keywords and inbound links are the other important components, which help brands establish on the Internet.

How this will be approached depends on the SEO - the search engine optimization strategy devised by the web makers to get the website established.

As it can be seen, the so called "search engines" play a key role. Google evaluates more than 200 components of a website in order to position it on the index. These components are relevant both to the site itself, its code, meta tags and structure, but also to the links crossreferencing it from other websites, its activity on social networks, viral marketing, etc. The wider the link building from prestigious websites, the higher the confidence in the website, which boosts visits.

Search engines show the headline, sometimes, the lead or a part of it. Certain search engines show a text abstract (140-160 char- acters), which contains the key words. This is similar to a subtitle in newspapers and different from a lead.

Example:

Title: Real (Madrid) made binding 1.6 billion dollar arrangements with Adidas.

Subtitle: "The white ballet" will sign its biggest ever deal with the sportswear company for the following 12 years.

A headline is very important on the Internet because it gives users a clue, while in newspapers they can see the full publication at once. However, if a reader doesn't get to the end of a certain newspaper article/story, he or she doesn't dispose of the paper all together but jumps to another article, unlike on the Internet, where, if a reader doesn't like the information, he/she merely goes to another website, where the same information might be better elaborated.

There is no need for an informative header, but, for the sake of search engines, it might have to contain keywords used multiple times and to pursue uniqueness. Similarly to press journalism, quotation headlines should be avoided except if they are very strong. As it is well known, a quotation in the headline shows the editor's helplessness.

After the end of the information, the editor adds the keywords (tags, labels) - the more, the better. Their right choice is critical for the website's good positioning.

\section{Editor's responsibility}

- To be well acquainted with the website's interface (the web interface is a set of tools helping users to interact with the website or with any app through a browser);

- To write headlines and subtitles in the designated boxes;

- To add tags (tags, key words or phrases). This is of particular importance for search engines. The more tags, the better.

- To add a fact box or the so called 'back- 
ground' information.

- To cross-reference other sites or documents by inserting text hyperlinks.

- To find an illustration and also describe it, which is important for the website. Each photo, which has been entitled and described can be helpful, because a web image search might transfer users to the website.

- To format the text and attach the illustration.

The illustration finding task can be handled by subscribing to photo agencies or using noncopyrighted images. Photography can also be purchased from specialized online stores. The Internet abounds in opportunities to richly illustrate a publication. In addition to one image or a gallery, videos, audios, tweets or Facebook posts can be added. Technical options are available thereto. Such illustration spares the need of using more text.

The advantage of the social networks is that where no subscriptions to agencies are affordable or a low cost is targeted, Twitter and Facebook images and videos are made usable through the embedding option. This is already being done by institutions, who are the first ones to upload images and videos on their social network accounts and they often do it ahead of agencies.

\section{Choice of information}

...is mainly entrusted to:

- Verified and highly reputable sources, usually international agencies and global media. They all have websites, they publish video materials. Sources should be quoted or, more convincingly, cross-referenced by links;

- Own production (if any);

- Television and radio stations, referencing is mandatory (although domestic practices show otherwise);

- Expert or recognized specialist opinions (with permission, tweets or Facebook posts can be used; no permission is required if such statements were published on the web accounts of institutions or politicians);

\section{Text organization}

On the web, it is important that a text be allowed some space to "breathe". This is why it has to be split into short paragraphs, 3-4 sentences each. Certain websites contain a special graphic form for quotations. One of the advantages of a website is that illustrations can be wrapped in the publication itself and thus make it a more enjoyable and easy to read. For instance, there are a lot of accessible info graphics on the websites of institutions, such as Eurostat, the World Bank, the IMF, etc.

\section{Target group}

Accurate assessment of the target group is of high importance. There are approximately 5 billion websites in the world. The difference between a website and a page, according to Bgpro.bg, is like the difference between a magazine and a page. "A page is simply part of the website, while a site is a system of interlinked pages with common design and navigation".

Preferably, a target group should not be very broad so that the team could focus and streamline its efforts.

The target group profile sets additional requirements to the online editor, such as:

- To be familiar with a maximum number of sources of specialized information (foreign sources included), which, in addition to expertise, involves the command of foreign languages;

- To have a fast response, a good general and linguistic culture;

- To have the required technical skills for positioning a text in the virtual domain. For the sake of the best positioning and the increase of the number of users, in addition to the website, the text must also be published in the social media, which opens at 
least three other communication channels: Facebook, Twitter, Google+. The website interface has a predesigned description form, which allows for devising an abstract of the article of up to 140 characters in the very course of the preparation, prior to publication. Twitter uploads this abstract. Facebook offers at least two options for publishing this information:

The full information is not posted (as we already noted, long texts put readers off). You either summarize the publication in two sentences or you use a provocative question, tease, comment, etc. Your smartness and resourcefulness matter if you want to make a reader click on a Facebook post and read it.

\section{Example One:}

Newspaper title: Krasimir Bezinski, one of CSKA's legends, passed away

Website title: One of CSKA's legends lost the fight against cancer

Facebook title: The tragic news, which made Berbatov shed tears

Twitter title: Former CSKA back player Krasi Bezinski dies aged 57. He will be buried in his home city of Blagoevgrad.

\section{Second example:}

Newspaper title: Grigor Dimitrov scores his poorest ranking since 2012.

Website title: Grigor collapses in yet another freefall.

Facebook title: For once, Grigor managed to get out of the "pit", will he make it again? Twitter title: Grigor Dimitrov dropped to be 43rd on the ATP rankings. Too bad if he fails to defend 90 points in Barcelona.

To publish information in a newspaper, Facebook or Twitter one must follow different principles in order to gain maximum outreach.

Let us take an example. Certain information is pending for publication and it seeks to get to a broad audience, regardless of whether it is published in a newspaper, a website or in social networks. There is no website without an account on Facebook, Twitter and/or Google+.

When posting information on Facebook, one publishes it with a header and illustration assigned to it "by birth", but the important aspect here is what text would the networks posting contain. The editor has several options to choose among: first and easiest, the full information goes on Facebook, we abridge it to the lead and leave it like this; second, we summarize it in an interesting way, taking 3, up to 4-5 lines, i.e. within the volume of a normal post, which can be read in full without the "See more" click; third, we publish an appetizer, a question, some joke tied to the information, a mere tease or an interesting quotation, smileys can be added and, based on the information, a hashtag, etc.

It all depends on editors' inventiveness and their intellectual and emotional capacity, and on the extent of their grasp of the Internet language, which is different from that in the newspapers. The Internet allows you to use smileys, hashtags and other options, which are available in networks to express thoughts, status, etc., while a newspaper has a more limited expressive resource in stock.

Twitter publishes a 140-character abstract, which editors write before publishing the article in the assigned box of the administrative panel.

Here is a funny, but true Instagram example of the various headline types in the social networks:

Facebook: I love muffins

Twitter: I eat \#muffins

Foursquare: Where I eat my muffin

YouTube: Me eating a muffin

LinkedIn: My skills include: eating muffins

The ending of a text is of no less importance. An article's conclusion has to be devised in a way to make sense and allow for rendering 
the information in its completeness. Prior to that, the editor must also have ensured that it supplies logical answers to all questions raised in the lead: who, what, where, when, why.

\section{Tabs/Sections}

Tabs or sections are an important element of the website as they provide the reader with instant navigation about where to locate each type of information, just as the sections of a newspaper correspond to its page headers. Therefore, it is of importance how they would be worded and laid out and working with a graphic designer since the very early stages of creating the website and its navigation is critical. There is a widespread perception that a staggering high-end design boosts the rate of website visits. Actually, what matters is content. There are websites of far inferior graphics, which generate higher readership due to their content.

It is good to brainstorm the entire team in the creation of sections/tabs. Unlike a newspaper, where one flips the pages to find the police chronicles or technology reviews, in a website it is all on the homepage, which leads to all other pages.

When the website is informative or informative and analytical, a section must be unambiguously clear to help readers locate the information they need. Preferably, it should be a single-word header, or, if this is impossible, it should consist of two, but short, words. The comments section must be taken good care of. Provided today's news oversupply, this is a good way to take the reader by surprise.

The section split-up and entitling is governed by the type of site and what it offers. Entertainment websites may have a more varied language in view of their users' lifestyle and also allow some freedom in the employment of graphical elements, text and the overall website structure. The relative share of textual information is much lower on such websites as they primarily focus on the illustrative or other type of graphical imagery.

\section{CONCLUSIONS}

An editor must be literate (linguistically and technically). Online editors handle more tasks in a shorter time than their paper counterparts, which entangles better organization and flexibility.

A fast response is a recommendable asset for the profession, including communicativeness and cooperativeness, provided that the job requires good teamwork organization, fast thinking and writing skills, an ability to analyze and reflect on the information, as there are practically an indefinite number of sources on the Internet.

Paradoxically, but in the fastest media (the Internet), a piece of news travels a longer route to reach people. Professionals are exposed to the highest time pressure and competition is huge. Online editors must be able to handle every step of the process: from the choice of information to text editing, illustration processing and video embedding (if any). They have to work in teams because everyone does everything. They have to find time to develop theirs and their colleagues' ideas, to moderate forums, to handle technical difficulties. And mostly, they should not forget that they have a responsibility to their users.

Sport journalists are placed in a very sensitive position to be able to combine the information operating technologies with presenting social position and development of social message according to the fundamental human principles. The combination between these two directions - technological knowledge and conceptual ability to present and defend sociocultural and moral cause is the main challenge for the future generation of sports journalists. This is why the academic scholarship for sports journalists must take more dynamic 
forms, causality-functional methods of study and should ensure a wide platform for sports journalism students to experiment with new creative ideas and decisions.

\section{REFERENCES}

Appel, V., Boulanger, H., Masou, L. (2010). Les dispositifs d'information et de communications: Concepts, usages et objects. Bruxelles.

Baskette, F., J. Sissors, B. Brooks. (2015). The Art of Editing in the Yearas of Convergence. New York.

Boczkowski, P. (2005). Digitizing the News: Innovation in online newspapers. Cambridge.

Boczkowski, P. (2010). News at Work-Imitation in Age of Information Abundance. Chicago.

Bowman, S., Willis, C. (2003). „We Media: How audiences are shaping the future of news and information", The Media Center, 2003. Available at: http://www.hypergene.net/ wemedia/weblog.php (accessed 27 February 2019).

Bruno, N. (2011). Tweet first, verify later: How real time information is changing the couverage of worldwide crisis events. Paris: Institut Reuters pour letude de journalism.

Curran, J., Seaton, J. (2010). Poewr without responsibility: Press, broadcasting and the Internet in Britian. 7th ed. London.

Davis, A. (2009). „Politics,journalism and news media: Virtual iron. Cages in new culture of capitalism", New media, old news: Journalism and democracy in the digital age. London.

DeTarle, A. (2006). Presse et Internet: Une chance, un defi: enjeux economiques, enjeux democratiques. Paris.

Deuze, M. (2008). ,,The Professional Identity of Journalists in the Context of Convergence Culture", Observatorio, No 7.
Domingo, D. (2008). „Inventing online journalism: A constructivist approach ton the developing of online news", in Paterson, $C$., Domingo, D. Making online news: The ethnography of new media production. NewYork.

Douglas, T. (2006). „How 7/7 democratized the media news", BBC, 04 July, 2006. Available at: http://news.bbc.co.uk/2/hi/ uk_news/5142702.stm (accessed 27 February 2019).

Este, J., Warren, C., Connor, L., Brown, M. (2010). Life in the clickstream II: The future of journalism. London.

Estienne, Y. (2007). Le journalism après Internet. Paris.

Eurobarometer $72(2009,2011,2015)$. L'Opinion publique dans L'Union Europeenne, TNS Opinion Social, realize a la demande de la Commission Europeenne. Bruxelles, 2009, 2011, 2015.

Feldman, E. (2002). The Writer's Guide to Self-Promotion \& Publicity.

Fogel, J., Payino, B. (2005). Une presse sans Goutenberg. Paris.

Friend, C., Singer, J. (2007). Online journalism ethics: Tradition and Transmision. New York.

Gallard, M., Petit, G. (2011). Barometre de confidence dans les media realise pour La Croix.

Ganny, D. (2009). Nouveaux medias: Mode d'emploi. Liege.

Harison, T., Barthel, B. (2009). „Wielding new media in the Web 2.0 Expoloring the history of engagement with the collaborative construction of media products", New Media and Society, No 11.

Hermida, A. (2011). ,Tweet the news: Social media streams and the practice of journalism", The Routledge Companion to News 
Journalism. 2. ed. New York.

Hermida, A., Fletcher, F., Korell, D., Logan, D. (2012). „Share, Like, Recommend: Decoding the social media news consumer", Journalism studies.

Hicks, W. and Holmes,T. (2002). Subediting for Journalists. London.

Hoebeke, S., Mouffe, B. (2012). Le droit de la presse: Presse ecrtite. Presse audiovisuelle. Preese electronique, 3th ed. Bruxeeles.

Holm, K. (ed.) (2000). Writer's Market 2011: 8000 Editors Who Buy What You Write. Writer's Market.

Jacobi, P. (1997). The Magazine Article: How to Think It, Plan It, Write It.

Jeaneret, Y., Souchier, E. (2003). Lire, ecrire. Recrire: objets, signes et pratiques des medias informatises. Paris.

Jenkins, H. (2006). Convergence Culture. New York.

Leiter, K., et al. (2003). The Complete Reporter: Fundamentals of News Gathering. Writing and Editing. 9th ed.

Livingstone, S. (2003). The Changing Nature of Auidences: From Mass Audience to the Interactive Media User in A companion to Media Studies. London.

Maigret, E. (2008). Sociologie de la communication et des medias. Paris.

Meikle, G. Redden, G. (2010). News online: transformations and continuities. New York.

Miller, S. (2004). „Miller Internet Data Integrity Scale", The New York Times, Mars 2004.

Newman, N. (2004). The rise of social media and its impact on mainstream journalism. Institut Reuters, Oxford.

Patterson, B. R., E. Coleman, P. Patterson (2003). The Editor in Chief: a Management
Guide for Magazine Editors. London.

Paulssen, S., Heinonen, A., Domingo, D. (2007). „Doing together: Citizen participation in the professional news making process", $O b$ servatorio, No3.

Plotnik, A. (1992). A modern Guide for Editors and Journalists. New York.

Poulet, B. (2009). La fin de journaux et Lávenir de l'infiprimation. Paris.

Purcell, K., Rainine, L., Mitchel, L., Rosenstiel, T., Olmstead, K. (2010). „Understanding the participatory news consumer", Pew Internet and American Life project. Available at: http://www.prewInternet.org/Reports/2010/ Online-News.asph (accessed 27 February 2019).

Quinn, S. (2005). Convergent Journalism: The Fundamentals of Multimedia Reprting. New York.

Rebillard, F. (2007). Le WEB 2.0 en perspective: Une analyse socio-economique de l'Internet. Paris.

Reich, Z. (2011). ,Source credibility and jourmalism: Betwwen visceral and dicoretional judgement", Journalisme practice, No 5.

Shaw, E. (2009). The Successful Writer's Guide to Publishing Magazine Articles.

Shudson, M. (2003). The Sociology of news. New York.

Singer, J., Hermida, A., Domingo, D., Heinonen, D., Paulussen, S., Reich, Z. (2011). Participatory journalism: Guarding open gates at online newspapers. New York.

Steinberg, S. (1996). Five Hundred Years of Printing. London.

Stepp, C. S. (ed.) (1989). Editingfor Today's Newsroom: New Perspectives for Changing Profession. Communication Textbook Series.

Strunk, W. Jr. and E. B. White (2000). The Elements of Style. New York: Macmillan. 
Swain, D. V. (2004). Creating Characters: or not: Factors influencing credibility on the How to Build Story People. New York. web", Journal of the American Society for In-

Tredan, O. (2007). „Le journalisme citoiy- formation Science and Technology, No53. en", Hermes, No 47.

Williams, A., Wardle, C., Wahl-Jorgensen,

Washington Post Deskbook on Style. K. (2011). „Have They Got news for Us”, (2001). 6d ed., complited and edited by Thomas W. Lippman. McGraw-Hill. Journalism practice, No5.

Wathen, C., Burkell, J. (2002). „Beleive Zinsser, W. (1994). On Writing Well. 5th ed. Harper \& Row.

Corresponding author:

Efrem Efremov Karanfilov

Faculty of Journalism and Mass Communication Sofia University „St. Kliment Ohridski”, 49 Moskovska Str Sofia 1000, Bulgaria E-mail: ekaranfilov@yahoo.com 